\title{
The Production of Callus, Shoot, and Rooted Plantlets of Rhododendron catawbiense 'English Roseum' from Florets
}

\author{
Jenna Sicuranza and Nathaniel A. Mitkowski ${ }^{1}$ \\ Department of Plant Sciences, University of Rhode Island, 9 East Alumni \\ Avenue, Suite 7, Kingston, RI 02881
}

Additional index words. IAA, 2iP, Anderson's medium

\begin{abstract}
The Rhododendron catawbiense (Michx.) varieties 'Roseum Elegans' and 'English Roseum' are the primary varieties of rhododendron sold in the northeastern United States; however, very little research has been published on their ability to produce shoots, roots, or plantlets in tissue culture. The suitability of two rhododendron varieties (including 'English Roseum') was examined using two different combinations of cytokinin and auxin in Anderson's rhododendron medium. It was determined that the variety 'Scintillation' performed poorly regardless of the media conditions used; however, 'English Roseum' produced callus and shoots using Anderson's medium and $4.0 \mathrm{mg} \cdot \mathrm{L}^{-1}$ IAA and $15 \mathrm{mg} \cdot \mathrm{L}^{-1} 2 \mathrm{iP}$. Rooted plantlets were produced using a rooting medium containing Anderson's medium and $4 \mathrm{mg} \cdot \mathrm{L}^{-1} \mathrm{NAA}$. The ability of 'English Roseum' to produce $35 \%$ successful plantlets under these conditions suggests that this variety is moderately suitable for micropropagation purposes.
\end{abstract}

The introduction of the pathogen Phytophthora ramorum (Werres, de Cock, Man int Veld) into the western United States has raised concerns over the transport of nursery materials from potentially infested areas of Washington, Oregon, and California into eastern regions of the country that have not yet tested positive for the pathogen. Because the pathogen is extremely destructive and has an extremely wide host range, it has been postulated that $P$. ramorum could asymptomatically infect a host such as Rhododendron catawbiense (Michx.) and be inadvertently transported across country (Englander and Tooley, 2003). Because Rhododendron L. is traditionally propagated clonally by cuttings, infected material could then be unintentionally multiplied or spread to the landscape. One solution to prevent this scenario is to produce new rhododendrons aseptically in a tissue culture system. Although this technique will not prevent plants from being infected in the field, it will ensure that only clean material is put into the field.

In New England, $R$. catawbiense 'English Roseum' and 'Roseum Elegans' are the primary varieties produced and sold. Although a number of researchers have investigated the potential for rhododendron production from tissue culture, there are few published reports of the in vitro suitability of these two varieties. A notable exception is the work by Meyer (1982) in which 'Roseum Elegans' was used. Meyer reports, however,

Received for publication 10 Oct. 2006. Accepted for publication 16 Nov. 2006.

${ }^{1}$ To whom reprint requests should be addressed; e-mailmitkowski@uri.edu. that the variety was reticent to reinitiate growth from florets and makes no mention of what percentage of culture attempts were successful with this or other varieties. The purpose of this research was to examine the suitability of $R$. catawbiense 'English Roseum' in comparison with other rhododendron varieties for use in the production of clean stock plants or potentially for the production of saleable plants.

\section{Materials and Methods}

Flower buds were collected from 25-yearold rhododendron plants growing outdoors at the University of Rhode Island East Farm Facility in Kingston, R.I. $\left(41^{\circ} 29^{\prime} \mathrm{N}\right.$, $\left.71^{\circ} 31^{\prime} \mathrm{W}\right)$. Buds used in trial 1 were collected in early Nov. 2004; buds used in trial 2 were collected in mid to late Dec. 2004. Two varieties of Rhododendron catawbiense, 'English Roseum' and 'Scintillation', were compared. A third R. catawbiense variety, 'Chionoides', was used in place of 'English Roseum' for control treatments in trial 1 because there were not enough 'English Roseum' florets available to complete the treatment. Three media treatments were compared for each $R$. catawbiense variety. Control media was prepared using Anderson's rhododendron salt mix (PlantMedia, Dublin, Ohio), $30 \mathrm{~g} \cdot \mathrm{L}^{-1}$ sucrose, and $14 \mathrm{~g} \cdot \mathrm{L}^{-1}$ agar (Difco, Sparks, Md.) (Anderson, 1975). Two plant growth regulator treatments were prepared by adding IAA and 2iP to this basal media. Medium I contained $1 \mathrm{mg} \cdot \mathrm{L}^{-1}(5.7 \mu \mathrm{M})$ IAA and $5 \mathrm{mg} \cdot \mathrm{L}^{-1}(24.5 \mu \mathrm{M}) 2 \mathrm{iP}$; medium II contained $4 \mathrm{mg} \cdot \mathrm{L}-1 \quad(22.8 \mu \mathrm{M})$ IAA and $15 \mathrm{mg} \cdot \mathrm{L}^{-1}(73.8 \mu \mathrm{M})$ 2iP (Meyer, 1982). One hundred florets of each $R$. catawbiense variety were grown on each media type for each trial. Florets were extracted similar to Meyer (1982). Buds were first soaked in a $0.5 \%$ sodium hypochlorite solution with three drops of Tween 20 for $5 \mathrm{~min}$. Buds were then rinsed in sterile water and the outer resinous scales were removed. Next, buds were soaked in a $0.5 \%$ sodium hypochlorite solution with three drops of Tween 20 for 20 min and rinsed in sterile water. As the inner papery scales were removed, florets were excised with as much pedicel tissue retained as possible. Florets were then pressed into a $100 \times 15-\mathrm{mm}$ Petri plate containing $50 \mathrm{~mL}$ of growth media so that the floret was submerged halfway in the media, pedicel first. Ten florets were placed on each plate. Plates were wrapped in aluminum foil and stored at $24{ }^{\circ} \mathrm{C}$ according to Meyer (1982). After 2 weeks, foil was removed and plates were returned to storage at $24{ }^{\circ} \mathrm{C}$ under cool white fluorescent light at an intensity of $50 \mu \mathrm{Mol} \cdot \mathrm{m}^{-2} \cdot \mathrm{s}^{-1}$ of photosynthetic photon flux in a growth chamber. Observations of growth were made at $\approx 3$ and 8 weeks after florets were plated. Five months after the original plating, only cultures produced during the second trial were transferred to a rooting medium. Sixty-three shoots were transferred to rooting medium plates composed of Anderson's rhododendron salt mix, $30 \mathrm{~g} \cdot \mathrm{L}^{-1}$ sucrose, $14 \mathrm{~g} \cdot \mathrm{L}^{-1}$ agar, $4 \mathrm{mg} \cdot \mathrm{L}^{-1}(21.5 \mu \mathrm{M}) \mathrm{NAA}$, and $1 \mathrm{~g} \cdot \mathrm{L}^{-1}$ activated charcoal. Plates were returned to incubation and observed after an additional 5 months. A statistical analysis of the data was performed using the General Linear Model procedure of SPSS (Chicago).

\section{Results and Discussion}

Both callus and shoot tissue produced from callus of $R$. catawbiense 'English Roseum' were successfully produced on both plant growth regulator-amended media (Fig. 1). The variety 'Scintillation' produced less growth on the same media regardless of plant growth regulator concentration, and all 'Scintillation' cultures had died in both trials by the eighth week after plating (Table 1). Statistical analysis was performed on the pooled data from both trials using the observations made at 8 weeks. Callus production by 'English Roseum' across media type demonstrated no significant difference

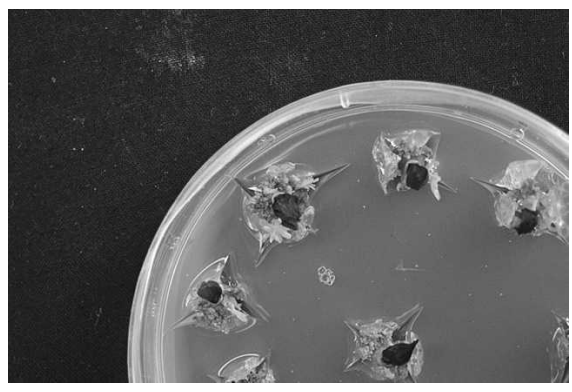

Fig. 1. Shoot and callus tissue produced by R. catawbiense 'English Roseum' after 12 weeks of incubation on medium II. 
Table 1. Number out of total florets and percentage of florets showing callus and shoot growth at 3 and 8 weeks.

\begin{tabular}{|c|c|c|c|c|c|}
\hline \multirow[b]{2}{*}{ Variety $^{z}$} & \multirow[b]{2}{*}{ Medium $^{y}$} & \multicolumn{2}{|c|}{ Trial 1} & \multicolumn{2}{|c|}{ Trial 2} \\
\hline & & 3 weeks $^{x}$ & 8 weeks & 3 weeks & 8 weeks \\
\hline ER & Control & - & - & $0 / 99(0 \%)$ & All dead \\
\hline $\mathrm{C}$ & Control & $20 / 94(21 \%)$ & All dead & - & - \\
\hline \multirow[t]{2}{*}{ ER } & I & $12 / 99(12 \%)$ & $32 / 90(36 \%)$ & $47 / 100(0 \%)$ & $69 / 100(69 \%)$ \\
\hline & & & $14 / 90(16 \%)$ & & $6 / 100(6 \%)$ \\
\hline \multirow[t]{2}{*}{ ER } & II & $41 / 100(47 \%)$ & $59 / 100(59 \%)$ & 94/96 (98\%) & $96 / 96(100 \%)$ \\
\hline & & & $31 / 100(31 \%)$ & & $28 / 96(29 \%)$ \\
\hline S & Control & $3 / 98(3 \%)$ & All dead & $0 / 100(0 \%)$ & All dead \\
\hline S & I & $53 / 99(54 \%)$ & All dead & No data & All dead \\
\hline S & II & $38 / 89(43 \%)$ & All dead & $19 / 100(19 \%)$ & All dead \\
\hline \multicolumn{6}{|c|}{$\begin{array}{l}\text { 'ER = 'English Roseum'; } \mathrm{C}=\text { 'Chionoides'; and } \mathrm{S}=\text { 'Scintillation'. } \\
\text { y }=\text { Anderson's medium with } 1 \mathrm{mg} \cdot \mathrm{L}^{-1} \mathrm{IAA} \text { and } 5 \mathrm{mg} \cdot \mathrm{L}^{-1} 2 \mathrm{iP} ; \mathrm{II}=\text { Anderson's medium with } 4 \mathrm{mg} \cdot \mathrm{L}^{-1} \mathrm{IAA} \\
\text { and } 15 \mathrm{mg} \cdot \mathrm{L}^{-1} 2 \mathrm{iP} \text {. }\end{array}$} \\
\hline
\end{tabular}

$(P=0.413, \alpha=0.05)$. An analysis of shoot production by 'English Roseum' across media type was also nonsignificant but at a lower $P$ value of 0.065 . An analysis of tissue proliferation across variety (excluding control treatments) was significant at $P=0.03$ for callus and $P=0.013$ for shoots. The control treatments were excluded from this last analysis because the variety 'Chionoides' was used as the control variety in place of 'English Roseum' in the first trial.

Cultures of 'English Roseum' from the first trial were discarded after 12 weeks, but cultures from the second trial were transferred to a rooting medium for an additional 5 months under the conditions previously described. After a total of 9 months in culture (the last five on rooting medium), $65 \%$ of the cultures transferred to the rooting medium had died, had not rooted, or were contaminated. Twenty-three transplanted shoots (35\%) of 'English Roseum' did produce substantial root systems and developed into vigorous plantlets (Fig. 2). Hardening off was not undertaken, but Anderson (1978) and Meyers (1982) indicate that unrooted rhododendron shoots produced in tissue culture root easily in a sand/sphagnum moss or peat/ perlite medium and the work of Almeida et al. (2005) supports this assertion.

According to Van Veen (1969), it is probable that 'English Roseum' is a selection originally made from 'Roseum Elegans'. These varieties do appear very similar in many respects so this assertion is not unfounded. If 'English Roseum' was selected from 'Roseum Elegans', it would be genotypically almost identical to 'Roseum Elegans'. As such, it would be likely to perform similarly to that variety in tissue culture. Meyer reports difficultly in inducing 'Roseum Elegans' to reinitiate growth, whereas in the current study, 'English

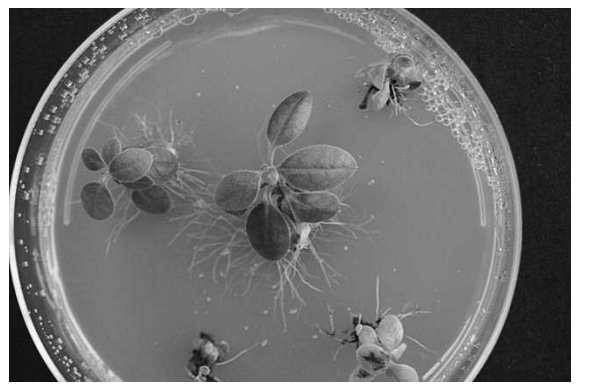

Fig. 2. Rooted plantlets of $R$. catawbiense 'English Roseum' after $\approx 11$ months on rooting medium containing Anderson's rhododendron salts and $4 \mathrm{mg} \cdot \mathrm{L}^{-1} \mathrm{NAA}$.

Roseum' was far more successful than 'Scintillation' and rooted easily. Although the reason for this discrepancy is unclear, numerous factors may be responsible. It is possible that 'English Roseum' is not derived from 'Roseum Elegans' and therefore would not be expected to respond similarly to the tissue culture environment. It is also possible that the season in which buds were harvested has an impact on culturability. All of the buds in this study were harvested in November or December, whereas Myers harvested buds from October until April.

Unfortunately, during the first trial of this research, the variety 'Chionoides' was used in place of 'English Roseum'. At the time of the trial, this was unavoidable and it was decided that tissues placed in the control treatment were unlikely to survive. As such, the use of an alternate variety for the control treatment would provide more useful information than using the alternate variety in one of the treatments using plant growth regulators. By the eighth week, all tissues placed in the control treatments of both trials had died, regardless of the variety used, suggesting that this was the most appropriate substitution.

This work demonstrates that the production of $R$. catawbiense 'English Roseum' plantlets in tissue culture is a relatively straightforward procedure; however, the examined protocols had a plantlet regeneration efficiency of only $35 \%$. Iapichino et al. (1991) were able to achieve $73 \%$ plantlet rooting of Rhododendron laetum $x$ aurigeranum on 1/4 Anderson's medium; however, survival after hardening-off was only $10 \%$. Recent work by Almeida et al. (2005) demonstrated $87 \%$ plantlet survival of endangered Rhododendron ponticum L. subsp. Baeticum (Boissier \& Reuter) HandelMazzetti. The high rate of survival was only possible with ex vitro rooting. Using in vitro rooting, survival dropped to $50 \%$. In the context of these other results, $R$. catawbiense 'English Roseum' seems moderately well suited to the tissue culture environment. It is possible that additional optimization of protocol could result in a higher efficiency. As such, the production of clean stock materials from tissue culture is a technically viable solution to aid in slowing the spread of $P$. ramorum. Unfortunately, this technique does not ensure that 1 - to 3 -year-old plants will not become infected when placed into the field or contaminated greenhouses.

\section{Literature Cited}

Almeida, R., S. Goncalves, and A. Romano. 2005. In vitro micropropagation of endangered Rhododendron ponticum L. subsp. Baeticum (Boissier \& Reuter) Handel-Mazzetti. Biodivers. Conserv. 14:1059-1069.

Anderson, W.C. 1975. Propagation of rhododendrons by tissue culture: Part 1. Development of a tissue culture medium for multiplication of shoots. Proc. Intl. Plant Prop. Soc. 25: 129-135.

Anderson, W.C. 1978. Rooting of tissue culture propagation of rhododendrons. Proc. Intl. Plant Prop. Soc. 28:135-139.

Englander, L. and P. Tooley. 2003. Plant hosts in the nursery industry-PLANTS MOVE! How might the movement of plants in the nursery industry contribute to the spread of Phytophthora ramorum to new areas? Sudden Oak Death Online Symposium. http://www.apsnet. org/online/SOD/Papers/Englander_Tooley/ default.htm (web site of The American Phytopathological Society). Accessed 2 Oct. 2006.

Iapichino, G., T.H.H. Chen, and L.H. Fuchigami. 1991. Aventitious shoot production for a vireya hybrid of rhododendron. HortScience 26: 594-596.

Meyer, M.M. 1982. In vitro propagation of Rhododendron catawbiense from flower buds. HortScience 17:891-892.

Van Veen, T. 1969. Rhododendrons in America. Sweeny, Kirst and Dim, Inc., Portland, Ore. 